\title{
TAILORING RESIDENTIAL ENERGY PROVISION STRATEGIES IN FAST-GROWING CITIES USING TARGETED DATA COLLECTION
}

\author{
A P Neto-Bradley ${ }^{1,2,3^{*}}$, R Choudhary ${ }^{2,3}$, A B Bazaz ${ }^{4}$ \\ ${ }^{1}$ FIBE CDT, University of Cambridge, Cambridge, United Kingdom \\ ${ }^{2}$ EECi, University of Cambridge, Cambridge, United Kingdom \\ ${ }^{3}$ Data Centric Engineering, Alan Turing Institute, London, United Kingdom \\ ${ }^{4}$ Indian Institute for Human Settlements, Bangalore, India \\ * Corresponding Author
}

\begin{abstract}
Understanding the factors that influence energy transitions at a household level, is essential for designing and implementing successful strategies to promote the uptake of cleaner fuels and deliver associated socio-economic benefits in the rapidly growing cities of the Global South. In India over 30 percent of urban households are still reliant on traditional fuels for some portion of their energy needs. Such fast-growing cities often display intra-urban inequalities of considerable magnitude which can condition individual access to resources and impact the effectiveness of energy provision strategies for individual city wards and districts. Intelligent use of data can play an important role in addressing this spatial inequality. Energy transitions are often conditioned by a complex interaction of economic and social factors. Analysis of targeted locally collected data in combination with secondary data sources can provide a means of identifying appropriate strategies and incentives for specific wards and communities that policy makers and planners can enact. In this paper we will use the results of a survey of 420 households in 7 city wards in Bangalore, India and show how this micro-scale survey data can be leveraged using a novel conceptual framework. The high resolution offered by the micro-scale dataset was used to identify 5 different clusters of households as a result of energy use patterns and associated non-income characteristics. These typologies may be used to inform policy makers, entrepreneurs, and engineers on the influence of non-income barriers to energy transition for different types of low-income communities.
\end{abstract}

\section{Introduction}

Reliable, secure, and affordable energy services are essential to ensuring sustainable economic and social development in the rapidly growing cities of the Global South, yet in India over 30 percent of urban households are still reliant on traditional fuels such as biomass and kerosene for some portion of their energy needs. Understanding the factors that influence energy transitions at a household level, is essential for successful strategies to promote the uptake of cleaner fuels and deliver associated socio-economic benefits. Fast-growing cities in India (and in the Global South) often display intra-urban inequalities of considerable magnitude which can condition individual access to resources and impact the effectiveness of energy provision strategies for individual city wards and districts. Existing datasets of households do not have sufficient resolution to understand the role that socio-economic and socio-cultural features play in the uptake of clean energy technologies.

Intelligent use of data can play an important role in addressing this spatial inequality. We argue that data collected through high-resolution targeted surveys can lend insights into conditions under which households will be predisposed to adopt specific residential energy technologies or fuels, and thus inform policy and planning. The high resolution offered by such a micro-scale dataset can be important to understand the non-income logic/patterns that govern energy transitions in these wards. Such data can be used to identify a set of features which can identify and describe a household's place within the energy transition, and highlight the barriers, obstacles and challenges that they face in adopting cleaner, more reliable fuels. This in turn could inform the tailoring of citywide policies and business models to the needs of different typologies of household. Our analysis in this paper provides a proof of concept for such an approach.

In this paper we report the results of a survey of 420 households in 7 city wards in Bangalore, India and show how this microscale survey data can be leveraged using a novel data-driven framework. Our data-driven framework for analysing energy transitions uses appliance ownership as a proxy for currently used energy services and conceptualises the uptake of appliances to be driven by non-income factors rather than a solely income-based change. The wards targeted by the survey cover a range of low-income typologies characterised by features that include income, livelihoods, dwelling type, sociocultural factors, access to fuels, and reliability of energy supply.

This approach has the potential to enable the design and implementation of smart energy provision strategies that are both tailored to specific wards and communities within a city 
and could also be incremental and updated with the regular input of additional surveys, or even real time utility metering.

\section{Background}

The 'Energy Ladder' concept as a hypothetical representation of the transition of household energy use from traditional fuels such as crop residue, animal waste, or firewood to modern fuels such as electricity and petroleum products assumes that there exists a hierarchy of energy technologies (or fuels) as steps or rungs on the path to clean modern energy use. Accordingly, different fuels on the ladder are ranked by perceived household preference in terms of cleanliness, convenience, and efficiency (Hiemstra-van der Horst and Hovorka, (2008)). This view of energy transitions assumes that households behave like utilitymaximising neoclassical consumers, implying that as income rises they will switch to using ever more sophisticated fuels and associated technologies which are higher ranked on the ladder (Hosier and Dowd, (1987)).

This concept has certain limitations; Its development was rooted in the need to progress from biomass to so called modern fuels such as electricity and LPG, with the resulting oversimplification that wood fuel is the 'fuel of the poor' (van der Kroon et al., (2013)). While a range of studies have found income to be an important factor in energy transitions it is not the sole factor influencing the uptake of modern fuels. Indeed an implication of a hierarchy of fuel preferences in the ladder model is that energy transitions are driven "not by an emerging desire for modern fuels so much as by socioeconomic changes, which help to break the constraints on their wider use" (Leach, (1992)). While these constraints can include income, other factors related to the practicalities of access to the fuel can also be an issue.

Early versions of the energy ladder model assumed a clean switch between fuels such that households use one technology at a time as they climb the ladder. In reality many households use multiple fuels to meet their energy needs, especially for cooking. This behaviour is a coping strategy in poorer households where secondary fuels and technologies are kept and used as an insurance policy against unreliable supply or unstable pricing of modern fuels (Hiemstra-van der Horst and Hovorka, (2008)). Indeed many studied based on the energy ladder show some contradiction with the basic assumptions of the model.

Energy provision serves to satisfy a social need and this aspect is often overlooked. Indeed, any techno-economic approach that puts excessive emphasis on monetary terms is likely to result in models that are inaccurate as they do not consider socio-political dynamics and unforeseen innovation (Jefferson, (2014)). From the perspective of social sciences, recent work considering energy in light of social practices has argued that rather than viewing energy use as a consequence of social systems, energy should be seen as an "ingredient of the social practices... of which societies are composed" (Shove and Walker, (2014), p. 46)

While studies continue to show that, in aggregate, there is a positive correlation between modern fuel use and income
(Davis, 1998), it is clear that other factors broaching social, cultural, and political dimensions are still not well understood. There is a lack of suitable and large enough data on these factors (Campbell et al., 2003).

In India, the Indian Human Development Survey (IHDS) is the most comprehensive nationwide dataset on household economic, socio-cultural, and energy use in India (Ahmad et al., (2014)), however the National Sample Survey Office (NSSO) also carries out regular nationwide surveys on energy use which covers appliance ownership, household fuel use, alongside characterising demographic indicators. The census data offers a snapshot every 10 years. The main limitation of all these national surveys is that despite having nationally representative samples, the sample size at state and district level is often too small to be able to draw conclusions with a relative degree of confidence. This is an issue particularly in urban areas where the existence of intra-city inequalities results in a need for locally tailored strategies, policies, and technologies (Bhan and Jana, (2015)).

\section{A wave analogy for energy transition}

We propose that energy transitions and associated appliance ownership broadly follows 'waves' of uptake conceptually illustrated in figure 1. Two distinct groups of appliances were identified from an exploratory analysis of the Indian Human Development Survey (IHDS-II) 2011 dataset:

- Class 1 which are LPG-associated cookware and lowpower electrical appliances. Class 1 is associated with an increase in use of LPG by a household and to a lesser degree electricity;

- Class 2 consisting of electricity intensive appliances. Class 2 is associated with a large-scale increase in electricity use.

The rationale behind the wave analogy is that uptake of any technology comprises early and late adopters, and these are not represented in the simple step change model. Geels ( (2002)) explains how technology transitions involve the accumulation of niches with specific groups of users shifting to a technology innovation, and this is a gradual process which involves experimentation, learning, and adjustments. Barriers such as information and financing constraints, for example, can slow this process, and the effect of these constraints will vary locally (Sagar and van der Zwaan, (2006)).

Our proposed wave analogy captures the distinction between early and late adopters through the leading and trailing edge of the wave. In figure 1 a graphical representation of these conceptual 'waves' are shown with a 'wave' for each class of appliances. The y-axis represents appliance ownership and the $\mathrm{x}$-axis represents either income or access to fuel. Note that each of these waves is bounded by the early and late adopters' curve, and the area between these two is the uptake wave encompassing all other households between these two extreme cases. This conceptualisation satisfies one obvious phenomenon which is that at any given income level households will exhibit a range of appliance ownership levels 


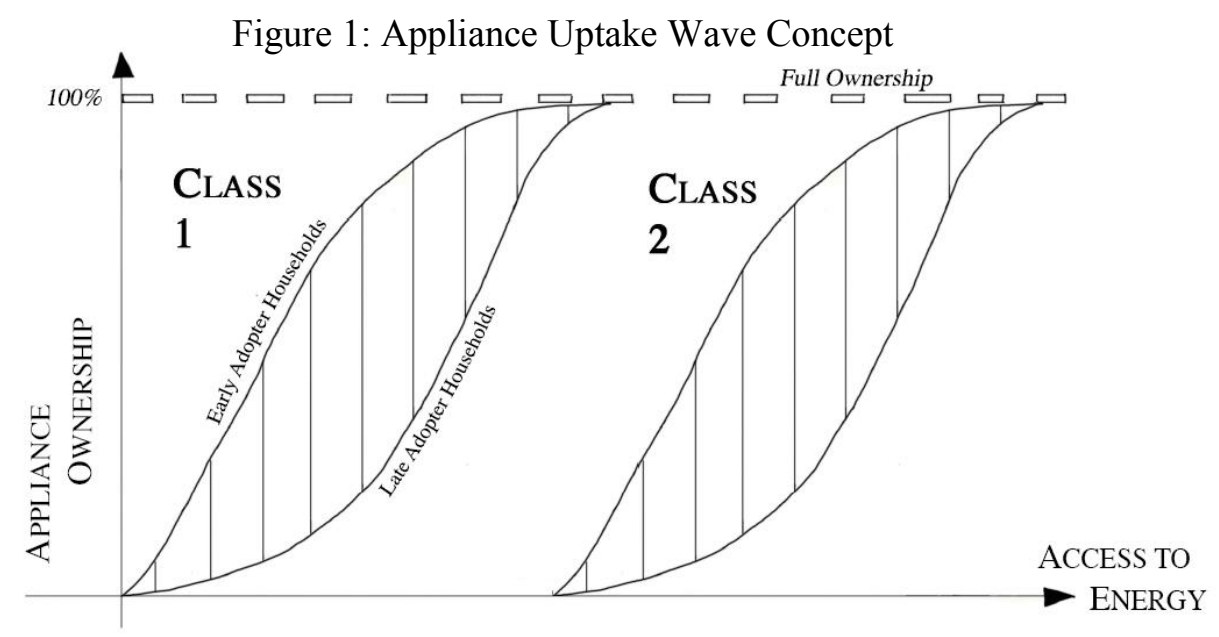

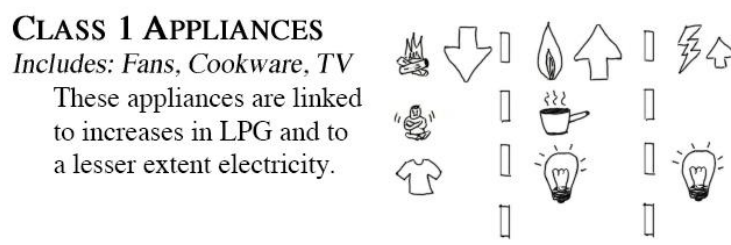

(and also fuel use mixes); Once the income threshold is satisfied, non-income determinants of household energy use come into play, determining when a household will get swept up in the "accumulation of niches" by a particular technology, and governs whether households are early adopters, latecomers, or somewhere in-between.

\section{Survey design}

To identify the presence of non-income barriers to energy transitions in Indian households requires an understanding of the multi-dimensionality of factors at the local level where they have the strongest influence. A survey of 420 households across seven wards in the city of Bangalore, was carried out to obtain a suitable dataset. This survey was designed to capture fuel stacking responses to uncertainty, as well as other nonincome phenomenon.

\subsection{Objectives of Survey}

Our survey aims to identify energy use trends and behaviours, directly addressing many of the limitations of these existing datasets. There are three major benefits this survey aims to deliver:

- $\quad$ Resolution - By selecting specific districts and urban and peri-urban wards within cities, and surveying a statistically significant number of households in each, there will be sufficient survey resolution to draw comparisons between these different neighbourhoods of households.

- Detailed Energy Use Breakdown - More detailed questioning on energy use will enable collection of data on the patterns of energy use, the services driving these, and fuel stacking by households.

- Non-income phenomena - By asking a wide range of questions on routines, lifestyle and socio-cultural

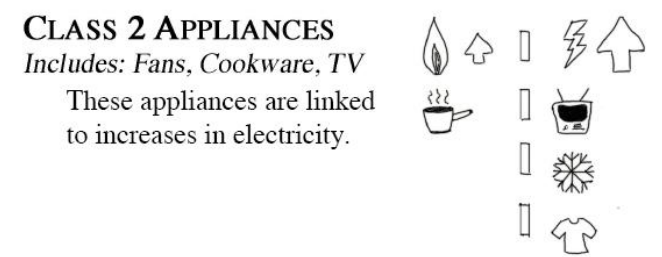

characteristics alongside the energy use and socioeconomic indicator questions, phenomena such as aspirations, time of use profiles, and convenience can be investigated.

\subsection{Multi-Disciplinary Best Practice}

This survey collects quantitative as well as qualitative data, dealing with subject matters ranging from highly technicallyoriented aspects of energy demand profiles, to social and cultural characteristics of households. A wealth of literature in the disciplines of Social Sciences concerns itself with the design of surveys and questions geared towards qualitative data collection. Given the mixed nature of data to be collected for this project, there are valuable lessons to be learnt from survey best practices across disciplines. Central to the design of the survey questions are the following three basic tenets: questions should be understood, questions should be answerable, and answer categories must fit with the intent of the question (Marsden and Wright, (2010)).

4.2.1 Pre-testing of Questions: Pre-testing of the survey instrument on a small group of respondents can single out questions that are difficult to understand or are interpreted in a manner other than intended by the researcher. Typically a small group of 15-25 respondents are used for pre-testing with a debriefing session following the survey to understand respondent's experience (Krosnick, (1999)). This survey used a more recent method known as cognitive pretesting where respondents "think aloud" while answering questions to allow interviewers to understand how the question is being interpreted (DeMaio and Rothgeb, (1996))

\subsection{Design of Survey Instrument}

The design of this survey incorporates the current best practice from social science quantitative survey methods. A series of 
expert elicitation interviews ${ }^{1}$ conducted in Bangalore during April 2018, were an important precursor to the development of this survey, and provides important first hand context, as well as insights on how to ask questions of households.

Table 1 summarises the structuring and types of variables collected by the 142 questions of the survey instrument. An underlying criteria for the design of the survey instrument was to ensure the potential for compatibility and cross-referencing with the existing IHDS and to a lesser extent other NSSO and census data. To allow for this a selection of 34 questions characterising the household in terms of household composition, dwelling type, caste, religion, expenditure, and education were taken from the IHDS-II (2011) survey (across sections 1-4 in table 1).

Table 1 Summary of survey data types and sections

\begin{tabular}{|c|c|}
\hline Section & Description of variables \\
\hline 1 & $\begin{array}{l}\text { Household Identification } \\
\text { Socio-cultural indicators e.g. Caste, Migration, } \\
\text { Dwelling Type }\end{array}$ \\
\hline 2 & $\begin{array}{l}\text { Household Roster } \\
\text { Demographic indicators e.g. Age, No. of } \\
\text { People in Household }\end{array}$ \\
\hline 3 & $\begin{array}{l}\text { Occupation and Salary } \\
\text { Economic indicators e.g. Occupation, Payment } \\
\text { Frequency, Expenditure }\end{array}$ \\
\hline 4 & $\begin{array}{l}\text { Education } \\
\text { Socio-economic indicators }\end{array}$ \\
\hline 5 & $\begin{array}{l}\text { Appliance Ownership } \\
\text { Ownership of energy related appliances and } \\
\text { equipment }\end{array}$ \\
\hline 6 & $\begin{array}{l}\text { Fuel Use } \\
\text { Fuel use magnitude, source, and availability }\end{array}$ \\
\hline 7 & $\begin{array}{l}\text { Energy Use Habits } \\
\text { Energy use practices e.g. switching behaviours, } \\
\text { factors influencing decisions, time of use, } \\
\text { access to programmes. }\end{array}$ \\
\hline
\end{tabular}

\subsection{Survey sample selection}

Correctly selecting the population to sample with this survey is crucial, and the objectives in terms of desired data must be balanced against the logistical and political practicalities of conducting surveys in specific wards or communities within a city.

The results of an expert elicitation survey helped understand the typical energy innovation adopter households both in terms of rural/urban localisation, monthly expenditure, and likely fuel use mix. Coupled with the findings from the IHDS-II this provided a basis for identifying suitable city wards to survey. The limited data available at a city-ward level in the 2011 census including limited data on the type of fuel used for cooking, lighting, and ownership of a group of electronic

\footnotetext{
${ }^{1}$ Expert elicitation is a method for obtaining expert knowledge on uncertain quantities in a quantifiable probabilistic form, done in such a manner to properly represent the expert's outlook.
}

appliances (TV, mobile phone, radio, scooter) was used to target wards.

From this analysis seven wards were identified, and they are shown and detailed in figure 2 and table 2 . These wards are of interest either for being located at a critical point on the appliance uptake wave, prevalence of solar energy systems despite low access to finance or home ownership, or for high use of alternative cooking fuels which imply that households are at a 'tipping point' having to choose between two prevalent options (Bhan and Jana, (2015)).

Figure 2 Bangalore wards selected for survey sample

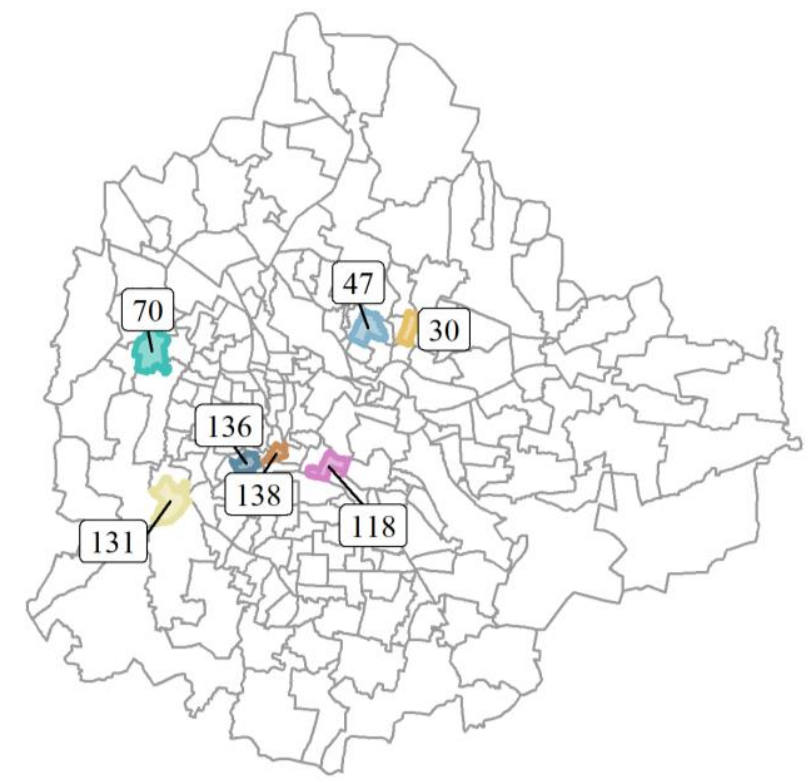

Table 2 Selected Bangalore ward characteristics

\begin{tabular}{ll}
\hline Ward no. & Key traits of interest \\
\hline 30 & $\begin{array}{l}\text { Relatively high use of solar systems \& } \\
\text { low access to banking }\end{array}$ \\
\hline 47 & Low gas use and low access to banking \\
\hline 70 & $\begin{array}{l}\text { High proportion of renters, low access to } \\
\text { banking and appliance ownership }\end{array}$ \\
\hline 118 & $\begin{array}{l}\text { Low access to banking, and appliance } \\
\text { ownership }\end{array}$ \\
\hline 131 & $\begin{array}{l}\text { High use of solar energy, low appliance } \\
\text { ownership and gas use }\end{array}$ \\
\hline 136 & $\begin{array}{l}\text { High kerosene use, low asset ownership } \\
\text { and access to banking }\end{array}$ \\
\hline 138 & $\begin{array}{l}\text { High kerosene use and proportion of } \\
\text { renters, low asset ownership and access } \\
\text { to banking }\end{array}$ \\
\hline
\end{tabular}

\subsection{Sample sizing}

This survey comprises a range of quantitative questions whose purpose is to characterise distribution of energy use and socioeconomic variables, as well as qualitative questions with 
categorisation which will not follow a normal distribution. The selection of sample size for qualitative surveys cannot be obtained purely by calculation and often relies on precedent and best practice (Kelley et al., (2003); Knol et al., (2010)). However as the quantitative data often requires a greater sample size for statistical significance purposes when compared to similar qualitative survey data, the sample was sized according to key quantitative data.

Recall that one of the objectives of this survey is to have a representative sample of households within each urban district surveyed. As a rule of thumb (Krithikadatta, (2014)) a sample size of 30 is sufficient to determine whether the variables associated with households (as summarised in Table 1) follow a normal distribution. However, we sized our samples such that we are within a $+/-10 \%$ error at a $95 \%$ confidence interval for both the continuous and categorical features of the households. A sample size of 60 households per ward was thus selected. In sum, we covered 7 wards, with a total of 420 households, and 22 key variables per household.

\subsection{Limitations \& considerations}

The descriptive quality and high resolution of our data provide a greater level of detail on energy use habits among lowincome slum households in India. However, they are limited in applicability by specifically pertaining to a specific agroclimatic, social, and political geography: namely Bengaluru. Further surveys across different states would be required to test the extent to which one could borrow strength across households located in different physical and socio-political conditions.

\section{Clustering methods}

Cluster analysis is commonly applied to identify subsets within a dataset that have similar characteristics. A number of algorithms exist to group data such that data within the subset is more similar to each other, as compared to the other identified subsets. Different algorithms use differing measures of similarity, and clustering procedures. For this study we have used a hierarchical clustering method.

Hierarchical clustering is an unsupervised machine learning method that identifies clusters based on the connectivity between data points. It can either take a top-down approach (Divisive Method) or a bottom-up approach (Agglomerative Method). A benefit of hierarchical clustering algorithms is that the iterative process produces a tree like structure of clusters which offers a more intuitive view of the clustering process and allows for better analysis of results, although the iterative nature of the algorithm makes it inefficient for extremely large datasets (Kassambra, (2017)). We used the agglomerative hierarchical clustering algorithm as it produced clear distinct clusters using a mix of categorical and numerical data while providing greater insight into the clustering process.

\subsection{Identifying Optimal Number of Clusters}

Hierarchical clustering like other unsupervised clustering methods requires the user to input the desired number of clusters. Several different methods for estimating the correct number of clusters exist, which aim to identify the number of clusters that maximises inter-cluster similarity and/or intracluster dissimilarity. The elbow method considers the total intra-cluster variation and seeks to minimise the within cluster sum of squares using the fewest number of clusters. The silhouette method, on the other hand, quantifies how well each point fits within its cluster - a sort of measure of cluster quality.

These measures alone can sometimes be ambiguous or be at odds with each other and as such the ultimate test is to perform the clustering analysis and observe whether the calculated number of clusters actually delivers the best inter-cluster similarity and intra-cluster dissimilarity.

\section{Identifying household typologies}

\subsection{Correlation Analysis}

In order to identify different household typologies with respect to energy use and transition behaviours, it helps to understand which subset of household variables are of most relevance. To identify these, we consider the correlation of variables applicable to all households with respect to both modern fuel use, and appliance ownership. The Spearman rank correlation coefficient was used to measure statistical correlation, as it is less sensitive to outliers, does not assume linearity, and can handle ordinal data. A +/- 0.5 threshold was applied to identify variables that are most relevant and monotonically correlated with fuel use and appliance ownership.

The correlated features are summarised in Table 3. Many of these are intuitively obvious. For example, appliance ownership and modern fuel use are strongly correlated, and hours of electricity availability and household size correlate positively with appliance and fuel use, a trend seen in other studies (Narasimha Rao and Reddy, (2007)). However, there are also some surprising findings, such as the correlation between adequate drinking water supply, and Class 1 appliance ownership. It is possible that this is an indicator of a household's access to utility infrastructure and public services.

Correlation between membership of a local association and liquid petroleum gas (LPG) use suggests the role of social dynamics. It is possible that being more involved in the local community helps spread awareness of the benefits of LPG as cooking fuel, or perhaps awareness of government programmes to support the uptake of LPG. It is also possible that collective adaptation to new energy lifestyles as a community is easier, especially in terms of shared experiences.

Another highly relevant finding was the relationship between income stability and appliance ownership and fuel use. Higher electricity and LPG use are correlated with households who get paid monthly. This means that households receive larger amounts of their income in one go, which helps them overcome some of the cashflow bottlenecks that can prevent households living on day-to-day income. It also provides some indication of their job security, which may lead a household to be more willing invest in a modern fuel or appliance with the knowledge that they will be able to afford the running costs long term. 
Table 3 Non-income factors with significant monotonic correlations with fuel use and appliance ownership

\begin{tabular}{|c|c|c|c|c|c|c|}
\hline \multirow{4}{*}{$\begin{array}{l}\text { Class } 1 \\
\text { Appliance } \\
\text { Ownership }\end{array}$} & & \multirow{2}{*}{$\begin{array}{l}\text { Livelihood } \\
\text { + Paid weekly }\end{array}$} & \multirow[t]{2}{*}{ Energy } & \multirow[t]{2}{*}{ Socio-cultural } & \multicolumn{2}{|l|}{ Economic } \\
\hline & Positive & & & & & \\
\hline & Monotonic & + Years of schooling & & & & \\
\hline & Correlation & $\begin{array}{l}+ \text { Adequate drinking } \\
\text { water supply }\end{array}$ & $\begin{array}{l}+ \text { LPG Use } \\
+ \text { Electricity Use }\end{array}$ & + Rooms in House & $\begin{array}{l}+ \text { Free } \\
\text { Recipient }\end{array}$ & Stove \\
\hline & $\begin{array}{l}\text { Negative } \\
\text { Monotonic } \\
\text { Correlation }\end{array}$ & - Paid daily & - Timber Use & $\begin{array}{l}\text { - Class } 2 \text { Appliance } \\
\text { Ownership }\end{array}$ & & \\
\hline \multirow{4}{*}{$\begin{array}{l}\text { Monthly } \\
\text { LPG Use }\end{array}$} & Positive & & & + Rooms in House & & \\
\hline & Monotonic & & & + Member of local & & \\
\hline & & $\begin{array}{l}\text { + Paid weekly } \\
+ \text { Work Hours }\end{array}$ & + Electricity Use & $\begin{array}{l}+ \text { Class } 1 \text { Appliance } \\
\text { Ownership }\end{array}$ & $\begin{array}{l}+\quad \text { Free } \\
\text { Recipients }\end{array}$ & Stove \\
\hline & $\begin{array}{l}\text { Negative } \\
\text { Monotonic } \\
\text { Correlation }\end{array}$ & - Paid Daily & - Stove Extractor & $\begin{array}{l}\text { - Member of socio- } \\
\text { cultural minority }\end{array}$ & & \\
\hline \multirow{4}{*}{$\begin{array}{l}\text { Class } 2 \\
\text { Appliance } \\
\text { Ownership }\end{array}$} & Positive & & & + Member of socio- & & \\
\hline & $\begin{array}{l}\text { Monotonic } \\
\text { Correlation }\end{array}$ & & & $\begin{array}{l}\text { cultural majority } \\
+\quad \text { Government }\end{array}$ & & \\
\hline & & + Paid Daily & + Extractor Stove & Programme Awareness & & \\
\hline & $\begin{array}{l}\text { Negative } \\
\text { Monotonic } \\
\text { Correlation }\end{array}$ & $\begin{array}{l}\text { - Paid Weekly } \\
\text { - Years of Schooling }\end{array}$ & $\begin{array}{l}\text { - Electricity Use } \\
\text { - Hours of Power } \\
\text { Supply } \\
\text { - Indoor Cooking } \\
\text { - Kerosene Use }\end{array}$ & $\begin{array}{l}\text { - Member of socio- } \\
\text { cultural minority } \\
\text { - Class } 1 \text { Appliance } \\
\text { Ownership }\end{array}$ & $\begin{array}{l}- \text { Years } \\
\text { Migration }\end{array}$ & Since \\
\hline \multirow{5}{*}{$\begin{array}{l}\text { Monthly } \\
\text { Electricity } \\
\text { Use }\end{array}$} & Positive & & & + Class 1 Appliance & & \\
\hline & Monotonic & & + Hours of Power & Ownership & + Years & Since \\
\hline & Correlation & $\begin{array}{l}\text { + Paid weekly } \\
+\quad \text { Adequate } \\
\text { water supply }\end{array}$ & $\begin{array}{l}\text { Supply } \\
\text { + LPG Use } \\
\text { + Indoor Cooking }\end{array}$ & $\begin{array}{l}+ \text { Member of socio- } \\
\text { cultural minority } \\
+ \text { Rooms in House }\end{array}$ & $\begin{array}{l}\text { Migration } \\
+\quad \text { Free } \\
\text { Recipients }\end{array}$ & Stove \\
\hline & $\begin{array}{l}\text { Negative } \\
\text { Monotonic }\end{array}$ & - Paid Daily & - Stove Extractor & $\begin{array}{l}\text { - Member of socio- } \\
\text { cultural majority }\end{array}$ & & \\
\hline & Correlation & & & $\begin{array}{l}\text { - Class } 2 \text { Appliance } \\
\text { Ownership }\end{array}$ & & \\
\hline
\end{tabular}

It is of course important to remember that these are merely the results of statistical correlation tests and that correlation does not imply causality; these relationships are purely explorative.

\subsection{Hierarchical Cluster Analysis}

The variables identified as significant through correlation coefficients were selected to perform our clustering analysis (all shown in Table 3). The optimum number was identified as being between 4 and 5 clusters, although initial clustering revealed that a 4 cluster solution resulted in two clusters that were not sufficiently distinct from one another.

Figure 3(b) of the dendrogram output from the agglomerative clustering of household variables shows that the households have been split into five clusters of different sizes, with two large clusters accounting for $64 \%$ of households, a further two smaller clusters of similar size accounting for $32 \%$ of households, and a final fifth cluster accounting for the remaining $4 \%$. While the clusters are not evenly sized they are distinct from one another and further separation would result in less distinctive clusters. Figure 3(a) and 3(c) show the clusters plotted against the first three principle components, showing the distinct clusters. Overlap across clusters are expected in socio-cultural data where often the combination of multiple variables results in the distinct patterns rather than merely one or two factors.

\subsection{Cluster characteristics}

A closer look at the principle component analysis biplots in figures 3(a) and 3(c) provides some insight into defining characteristics of the clusters. Notice how the first principle component is largely defined by Year's Since Migration and a Trade-off between LPG use or Kerosene use. Households in cluster two on the negative side of the PC1 axis are defined by their recent migration and higher kerosene use. At the other end of the PC1 axis cluster 5 is characterised by higher LPG use and lower kerosene use.

Orthogonal to this principle component 2 (PC2) is explained by characteristics including electricity use, and the size of the household, and caste (from lower to higher). This distinguishes the higher caste but lower electricity using cluster 1 , from the higher electricity using and larger households of cluster 4 . In figure 3(c) we can see how in the third principle component there appears to be a trade-off between years since migration and income frequency. 
Figure 3(a) Cluster analysis results in principle components $1 \& 2$

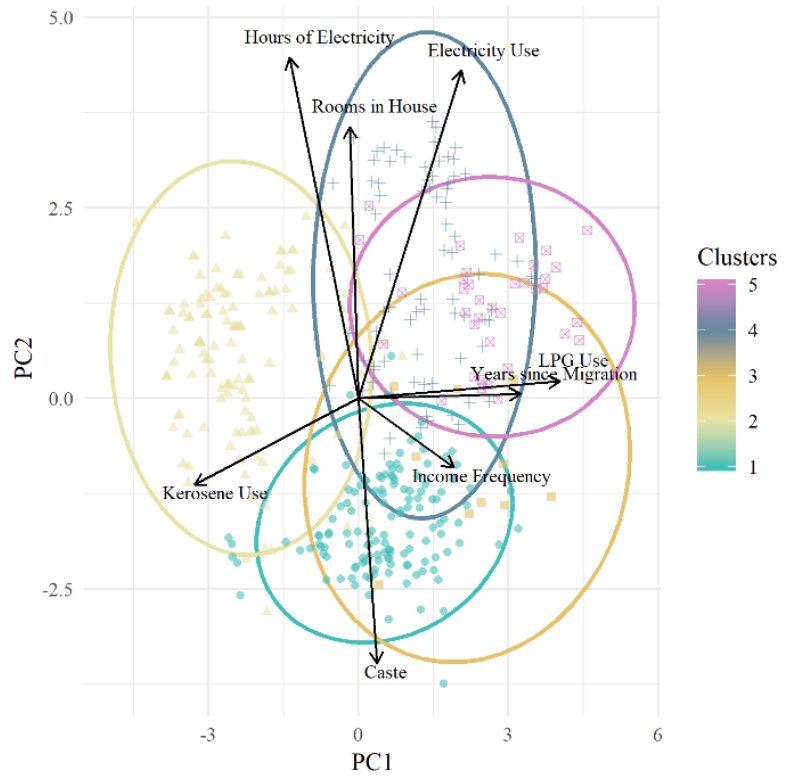

Figure 3(b) Cluster analysis dendrogram

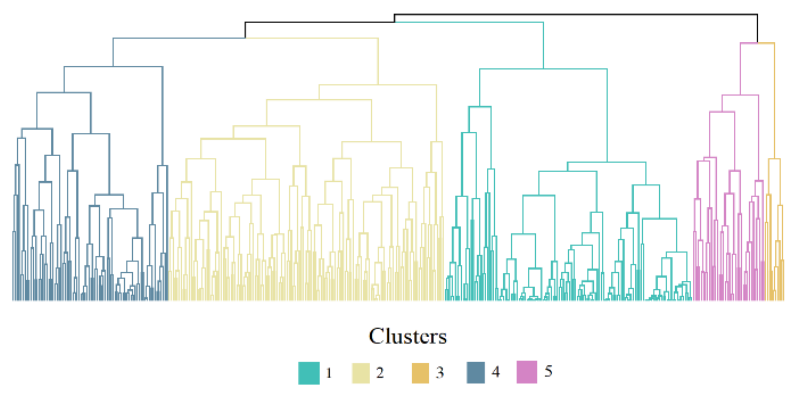

Figure 3(c) Cluster analysis results in principle components 2 and 3

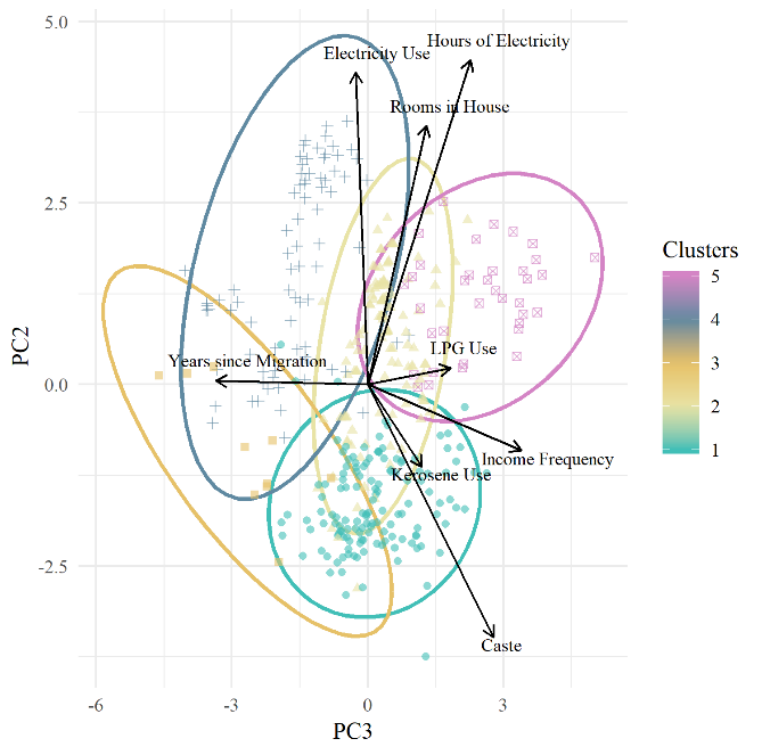

When we consider the principle component analysis biplots along with the dendrogram in figure 3(b) we can begin to better understand why clusters $3 \& 5$ which represent only $10 \%$ of the population surveyed are singled out. The separation between the points representing these two groups of households and the remaining three clusters is significant, with a high-level branch off from the other three clusters, suggesting a fundamental difference in the nature of these clusters.

The results of this clustering analysis are of interest because they show distinct subsets of households that not only display different energy use and transition behaviours but are defined by distinctly different socio-cultural characteristics despite having virtually identical incomes. All clusters have mean monthly expenditures within the range of 4100-4600 rupees (INR). We singled out six of these key explanatory variables for closer analysis shown in figures 4-9.

Figures 4-9 show the appliance ownership, electricity use, frequency of income payment, minority status, time since migration to the city, and awareness of government programmes across the five clusters. One prominent differentiating characteristic between clusters is the time since migration to the city shown in figure 7.

Table 3 showed that time since migration is linked to class 2 appliance ownership and electricity use, with longer established households displaying greater ownership and electricity use than recent arrivals. There is some intuitive sense to this, as low income households will have to save up to buy new appliances which means the longer a household has been in existence the more appliances it will have accumulated.

There is one notable exception which is the case of clusters 3 and 5, where cluster 3 represents all non-migrant households (defined as households whose family arrived over 90 years ago) and cluster 5 represents a group of second generation rural-urban migrants who have been in Bangalore for 30-45 years. Cluster 3 households have relatively low appliance ownership and electricity in relation to the time the household has existed, whereas cluster 5 would seem to represent households who despite being relatively more recent arrivals have a higher than expected appliance ownership. Cluster 5 households have a high uptake of appliance and electricity use for appliance ownership.

A related variable in this analysis is awareness levels of government programmes for clean cooking fuel, and electricity uptake. More recently arrived households, with a greater proportion of households paid daily or weekly seem to be more aware of such subsidies, and access programmes, whereas longer established household seem to be less aware of these. It would stand to reason that these more recently arrived households will be more aware of help available to them as they may struggle to make ends meet.

As already mentioned, frequency of payment as shown in figure 6 is an important factor in household energy use behaviours. Many low-income households are paid on a dayto-day basis which restricts cash flow, limiting purchasing power, as well as resulting in lower job and income security. This would appear to have an impact on acquisition of appliances and uptake of modern fuel use with clusters 2 and 4 having the highest proportion of daily paid households, and both have rather low rates of appliance uptake when time since arrival is taken into consideration. 
Figure 4 Class 1 appliance ownership by cluster

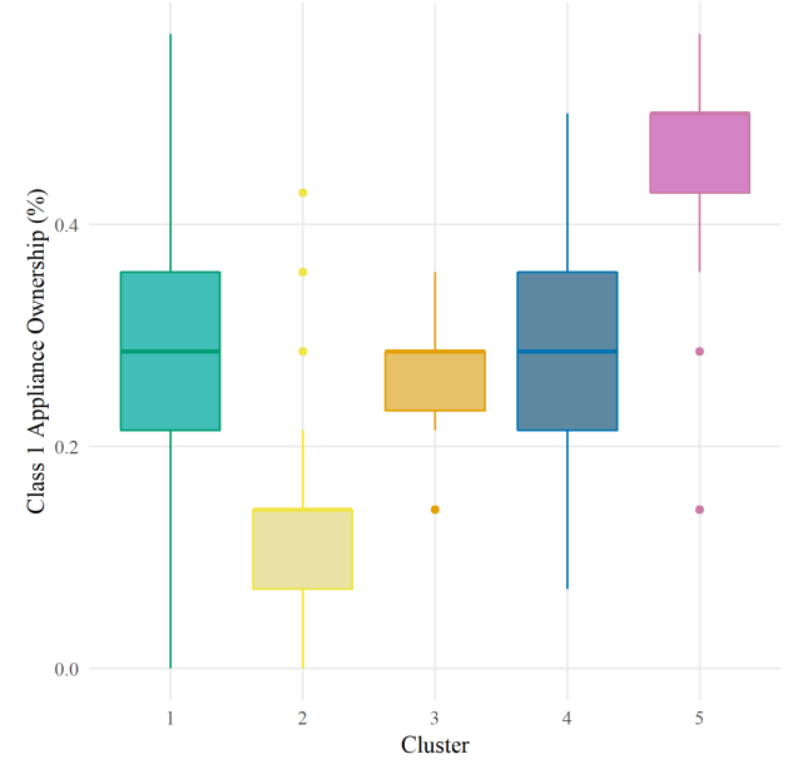

Figure 5 Electricity use by cluster

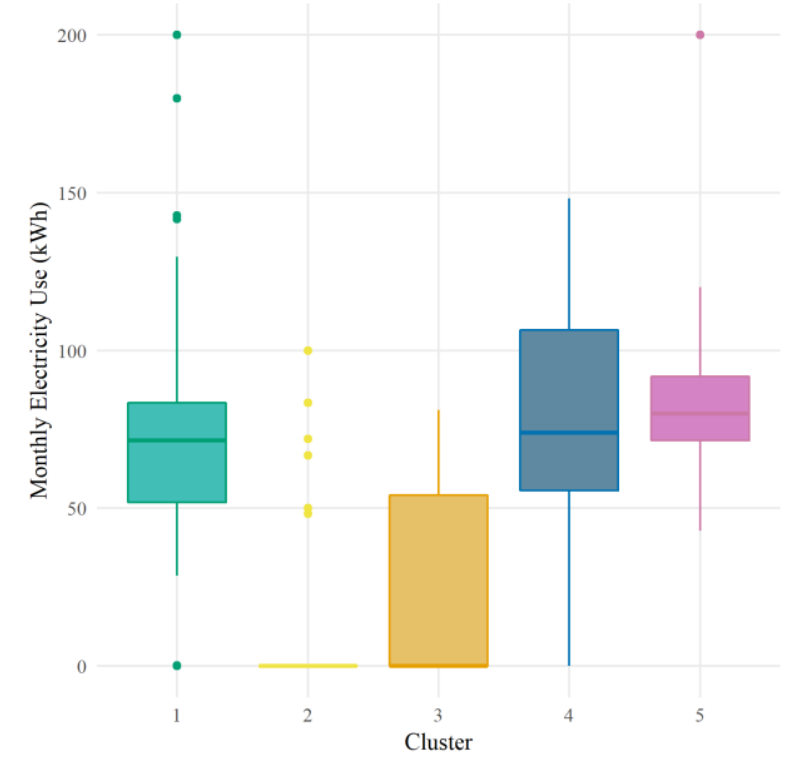

Figure 6 Frequency of payment by cluster

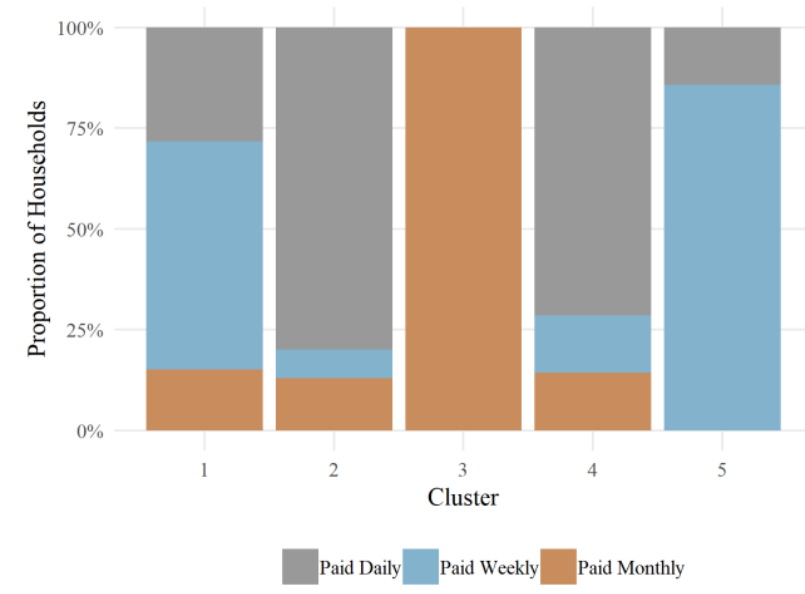

Figure 7 Years since migration to city by cluster

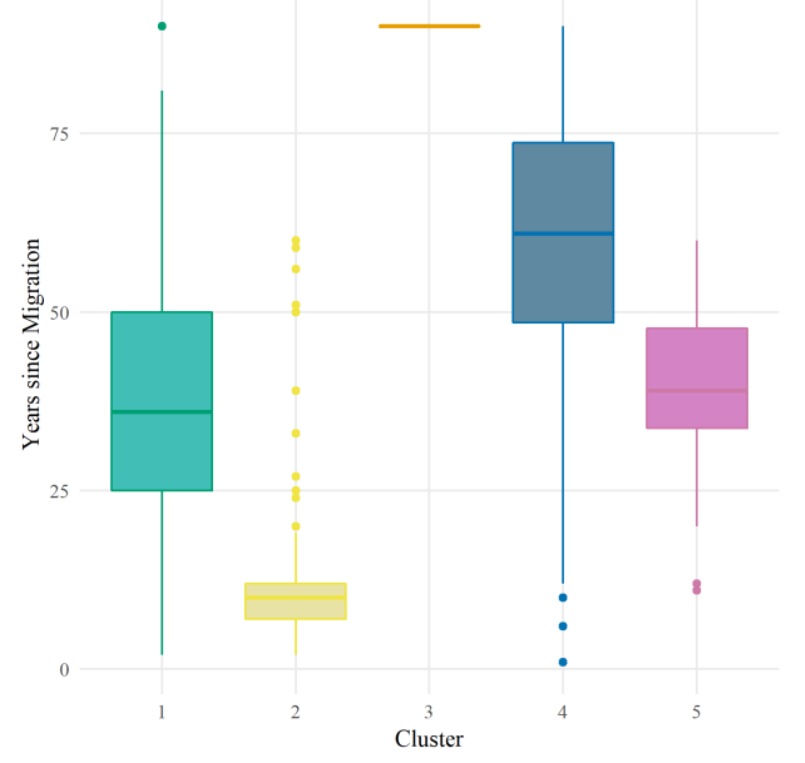

Figure 8 Split between minority and majority religions by cluster

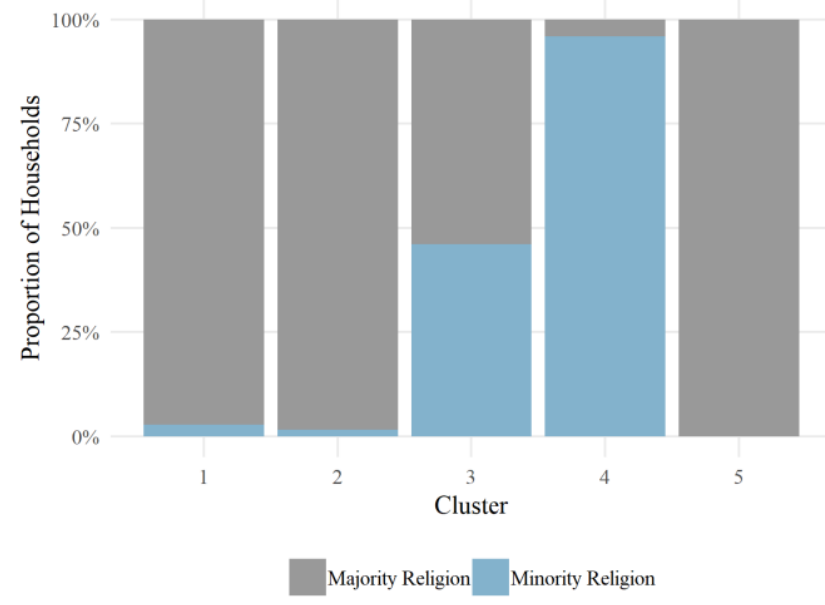

Figure 9 Awareness of government programmes to promote clean fuel uptake

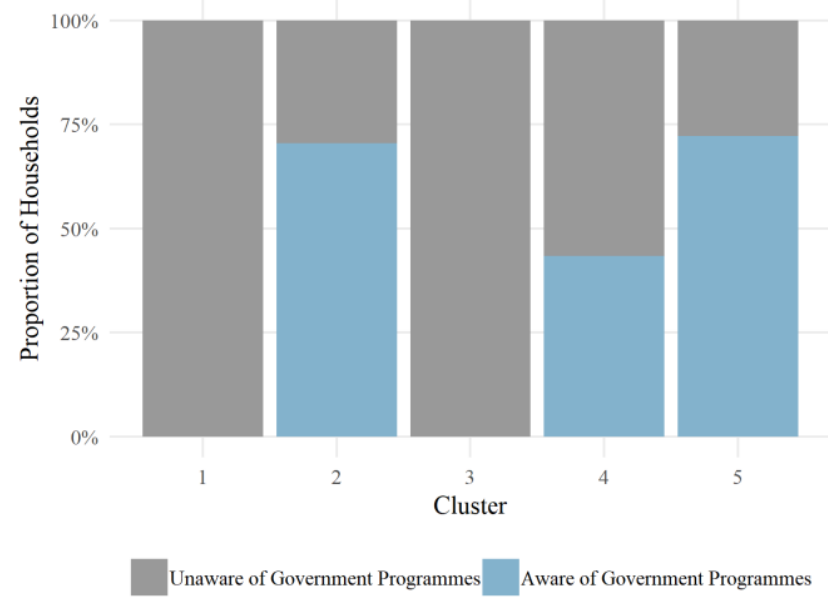


Socio-cultural grouping along lines of religion and caste can often play a role in functioning and organisation of a community. It is interesting to note in figure 8 that clusters 3 and 4 with significant proportions of religious minorities display relatively low electricity use and appliance ownership for their time since migration. This may point to differing social norms, difficulties with the dissemination of information in such communities, or indeed limited access to resources.

There are two key recommendations that the findings of this analysis support. Firstly, it is important to provide better access to financial arrangements to help low-income households paid on a day-to-day basis in order for them to afford upfront costs, 'lumpiness' of payments, and risks of adopting a cleaner more modern fuel. Households paid on a daily basis (who are also often recent migrants to the city) in particular are at risk of being stuck in a 'biomass trap' where they cannot afford the upfront cost required to purchase a cleaner stove or fuel. Secondly, this data makes a strong case for awareness programmes targeted at more established households and communities who have less awareness of available support and the risks of using traditional cooking fuels indoors.

A key finding from this data and analysis is that no single factor can fully explain the energy use behaviours and habits of a group of households, and it is only a combination of these key variables that can provide a robust narrative. Further analysis of this data, long with data from other cities and census data may provide greater insight on the typologies of household and if any of these are common across India, or indeed of relevance in other fast-growing cities of the Global South.

\section{Conclusions}

The results of the targeted household energy use survey amongst low income households in Bangalore has shown combinations of distinct typologies of low-income household energy transition behaviours, characterised by several nonincome variables including migration, employment, religion, and education. Other factors including the meals cooked in a day, religion, and education are also linked with these different typologies and may also help explain the trends observed.

A key finding is that financial arrangements to help lowincome households paid on a day-to-day basis are essential to helping households deal with upfront costs and risks of adopting a cleaner more modern fuel.

Many lower-income households in cities originate from rural regions and smaller cities, and thus understanding the impact of time since arrival is important. As shown, the most recent migrants often are most aware of government support programmes, and the risks of using traditional fuels indoors.

Longer-term resident low-income households have poorer awareness of support available and the risks of using traditional fuels indoors, likely a result of falling through the cracks of previous efforts to improve clean cooking fuel use in households. Non-migrant households despite their longevity in the city, are often stuck in traditional fuel use habits. Both these groups would likely benefit from tailored awareness raising programmes.

Our targeted survey approach could offer policy makers, city planners, and other stakeholders a relatively low cost, quick, and insightful tool to identify the combination of variables that identify energy poverty and provision policies to better meet the diverse needs of low-income residents of mega cities of the Global South.

\section{Acknowledgements}

The authors are grateful for EPSRC support through the CDT in Future Infrastructure and Built Environment (EP/L016095/1) and to Indian Institute for Human Settlements, India.

\section{References}

Ahmad, S, Mathai, MV, Parayil, G, (2014). Household electricity access, availability and human well-being: Evidence from India. Energy Policy 69, 308-315. https://doi.org/10.1016/j.enpol.2014.02.004

Bhan, G, Jana, A, (2015). Reading Spatial Inequality in Urban India. EPW I, 49-54.

DeMaio, TJ, Rothgeb, JM, (1996). Cognitive interviewing techniques: in the lab and in the field, in: Answering Questions. Jossey-Bass, San Francisco, pp. 177-96.

Geels, FW, (2002). Technological transitions as evolutionary reconfiguration processes: a multi-level perspective and a casestudy. Research Policy, NELSON + WINTER + 20 31, 12571274. https://doi.org/10.1016/S0048-7333(02)00062-8

Hiemstra-van der Horst, G, Hovorka, AJ, (2008). Reassessing the "energy ladder": Household energy use in Maun, Botswana. Energy Policy 36, 3333-3344. https://doi.org/10.1016/j.enpol.2008.05.006

Hosier, RH, Dowd, J, (1987). Household fuel choice in Zimbabwe: An empirical test of the energy ladder hypothesis. Resources and Energy 9, 347-361. https://doi.org/10.1016/0165-0572(87)90003-X

Jefferson, M, (2014). Closing the gap between energy research and modelling, the social sciences, and modern realities. Energy Research \& Social Science 4, 42-52. https://doi.org/10.1016/j.erss.2014.08.006

Kassambra, A, (2017). Practical Guide to Cluster Analysis in R. Unsupervised Machine Learning (Multivariate Analysis I). STHDA.

Kelley, K, Clark, B, Brown, V, Sitzia, J, (2003). Good practice in the conduct and reporting of survey research. Int $J$ Qual Health Care 15, 261-266. https://doi.org/10.1093/intqhc/mzg031

Knol, AB, Slottje, P, van der Sluijs, JP, Lebret, E, (2010). The use of expert elicitation in environmental health impact assessment: a seven step procedure. Environmental Health 9, 19. https://doi.org/10.1186/1476-069X-9-19

Krithikadatta, J, (2014). Normal Distribution. J Conserv Dent 17, 96-97. https://doi.org/10.4103/0972-0707.124171 
Krosnick, JA, (1999). SURVEY RESEARCH. Annu. Rev. Psychol. 50 , $537-567$ https://doi.org/10.1146/annurev.psych.50.1.537

Leach, G, (1992). The energy transition. Energy Policy, Energy and the Third World 20, 116-123. https://doi.org/10.1016/0301-4215(92)90105-B

Marsden, PV, Wright, JD, (2010). Handbook of survey research., 2nd ed. / edited by Peter V. Marsden, James D. Wright. ed. Bingley : Emerald Group Pub., 2010., Bingley.

Narasimha Rao, M, Reddy, BS, (2007). Variations in energy use by Indian households: An analysis of micro level data. Energy 32 ,

https://doi.org/10.1016/j.energy.2006.03.012
Sagar, AD, van der Zwaan, B, (2006). Technological innovation in the energy sector: R\&D, deployment, and learning-by-doing. Energy Policy 34, 2601-2608. https://doi.org/10.1016/j.enpol.2005.04.012

Shove, E, Walker, G, (2014). What Is Energy For? Social Practice and Energy Demand. Theory, Culture \& Society 31, 41-58. https://doi.org/10.1177/0263276414536746

van der Kroon, B, Brouwer, R, van Beukering, PJH, (2013). The energy ladder: Theoretical myth or empirical truth? Results from a meta-analysis. Renewable and Sustainable Energy Reviews 20, 504-513. https://doi.org/10.1016/j.rser.2012.11.045 